\title{
REVIEW
}

\section{Reuse versus single-use catheters for intermittent catheterization: what is safe and preferred? Review of current status}

\author{
MÅ Håkansson
}

Study design: This is a narrative review summarizing prevalence and background of reusing catheters for intermittent catheterization. It also compares complications related to reuse versus single use.

Objectives and setting: The objective of the review is to highlight the on-going debate regarding whether reuse of catheters is as safe as single-use technique and investigate why reuse is common in some countries (for example, Australia, Canada and the United States).

Methods: The review is the result of systematic searches in several databases (for example, MEDLINE, EMBASE and CINAHL) using predefined key words and search strategy.

Results: The literature does not explicitly recommend reuse but instead proposes patient-oriented choice. Even so, the prevalence of reuse is $\sim 50 \%$ in some regions. Both off-label reuse and reuse of catheters intended for multiple use occur. The former is not legally supported. There seems to be no consensus on how many times a catheter can be reused or how to clean it. Poor compliance and efficacy of cleaning techniques have been reported, increasing the risk for introducing bacterial contamination. The literature supports the use of single-use hydrophilic catheters to reduce the risk of urethral trauma and urinary tract infection with a reported incidence of the latter between 40 and $60 \%$, as compared with $70-80 \%$ for reuse catheters. Further clinical studies are however needed to verify/reject a difference.

Conclusion: Complications associated with reuse need to be further investigated. Although awaiting evidence, it is recommended to use a confirmed safe, patient-preferred, noninfecting and nontraumatic technique for intermittent catheterization.

Spinal Cord (2014) 52, 511-516; doi:10.1038/sc.2014.79; published online 27 May 2014

\section{INTRODUCTION}

Reuse of urinary catheters among patients who practice intermittent catheterization is common, especially when financial reimbursement is not covered by the health-care system. Reuse is practiced in developing countries and also in Australia, Canada and the United Status, whereas other countries reimburse and use single-use catheters. The reasons for this imparity could be searched within legal requirements, published guidelines and how to view costs. In addition, there is an on-going debate as to whether reuse is as safe as a single-use technique and also whether there is a difference in urinary tract infection (UTI) rate between clean and sterile techniques. The objectives of this narrative review are to summarize prevalence, regulatory background, views of published guidelines, cost implications and issues related to reusing catheters for intermittent catheterization. With this as a basis, comparisons between reported complications for reuse versus single-use catheters are highlighted. The overall purpose of the review is to summarize all relevant parts needed to make an informed decision on the best catheter choice for patients practicing intermittent catheterization. The review also points out gaps in evidence and includes recommendations for future research.

\section{MATERIALS AND METHODS}

A literature search was performed in MEDLINE via PubMed in October 2013 using the keywords 'intermittent catheter' AND 'reuse' or 'intermittent catheter*' AND 're-use' that resulted in 18 publications. Similar searches were made in EMBASE, resulting in 14 publications, in Thomson Reuters Web of Knowledge, resulting in 11 publications, in EBSCO Discovery database covering, for example, CINAHL and full-text MEDLINE, resulting in 36 publications and in the Cochrane Library, resulting in one Cochrane review and three trials. All publication lists were screened for relevant citations, that is, publications referring to reuse of catheters used for intermittent catheterization and/or impact on clinical complications and outcomes because of different catheterization techniques. In addition, relevant publications found from cross-references have been added to the list of relevant citations. Selected citations are specified in the reference list.

\section{General assumptions}

The following general assumptions have been made for the purpose of this review. First, the term 'hydrophilic' is used as a generic term for all different types of coated catheters with a smoothening surface even though it is recognized that different types are available, such as described by Nazarko ${ }^{1}$ in 2012, for example, coated catheters activated with water or pre-packed with gel or fluid reservoir. Second, the lack of head-to-head comparisons between reuse 
and single use of catheters with regard to UTI frequency and other complications has driven the review to also consider comparisons between hydrophilic and uncoated plastic catheters in general. It is assumed that potential differences found between single-use hydrophilic catheters and reused uncoated plastic catheters would be as great or greater as those found between single-use hydrophilic and single-use uncoated plastic catheters

Third, this review has considered publications of all evidence levels and has with few exceptions been limited to clinical papers only. It has used an 'all-in' approach based on the limited number of appropriate publications investigating the specific research question. For this reason, a formal meta-analysis was not applicable.

Finally, more recently published reviews and citations have generally been chosen in favour of older ones, but it should be noted that, for some citations, reference is made both to review articles, including them, and to the single publication. In contrast, some articles published less recently have been excluded when they were included in review articles. To mitigate the risk of bias of individual studies, data from each study are only reported once.

\section{RESULTS}

\section{Prevalence}

Reuse of catheters for intermittent catheterization is common in different regions depending on the health-care system. ${ }^{2}$ This review defines reuse as both off-label reuse, that is, reuse of devices intended for single use such as uncoated polyvinyl chloride (PVC), hydrophilic or gel catheters, and as reuse of devices labelled and intended for multiple use such as silicon, rubber (latex), glass or stainless steel catheters. Reasons for reuse of medical devices are mainly related to proposed cost and environmental savings, but reuse is also practiced because there is a lack of safety data on the incidence of crossinfection and device malfunction compared with single use. ${ }^{3}$ Limitation of resources is also an important factor, especially for developing countries. ${ }^{4,5}$ The prevalence of reuse is difficult to estimate and would reasonably differ between different regions. In the United States, the Centers for Medicare and Medicaid Services changed their policy in 2008 to reimbursing up to 200 catheters per month for patients practicing intermittent catheterization. ${ }^{6}$ One could assume that this would more or less eliminate the need for reuse, but high rates of catheter reuse are still reported. For instance, in 2013, Bolinger and Engberg ${ }^{7}$ reported $56 \%$ reused catheters, with a median of 20 times each, and referred high reuse rates to reimbursements of a more limited number of catheters per month by private insurers. Wilde et al. ${ }^{2}$ reported $35 \%$ reuse in their sample studied in 2008-2009. Although the reuse frequency is lower in both reports ${ }^{2,7}$ than in Sherbondy et al. ${ }^{8}$ who reported in 2002 that only $17 \%$ of catheters used were disposed of after a single use, substantial reuse rates could be expected for the United States, of $\sim 40-50 \%$. In Canada, Woodbury et al. ${ }^{9}$ registered reuse in approximately half of the patients they studied for both uncoated (47\%) and hydrophilic (46\%) catheters, and it has been reported that cleaning catheters is the norm. ${ }^{2}$ In Australia, reuse is common in the community setting and the reported prevalence would be at least $47-50 \% .{ }^{10}$ There seems to be no consensus for how many times a catheter should be reused. Getliffe et al. ${ }^{11}$ described different set-ups in studies, with reuse varying from $24 \mathrm{~h}$ ( 5 times) to 7 days, whereas other authors present a reuse of catheters with a median of 20 times each ${ }^{7}$ or an average reuse of 3 years. ${ }^{12}$ The Medical Advisory Secretariat in Canada described in their report from 2006 an assumed use of one catheter per day, but found a use of one catheter per week was common in reality. ${ }^{13}$ The latter is also described in the Australian community by Leek et al. ${ }^{10}$ Practiced reuse is dominant in the community setting whereas singleuse and sterile techniques are recommended in the hospital setting to avoid the risk of infection. ${ }^{14,15}$

\section{Regulatory background}

Regulatory requirements for off-label reuse are generally the same as for original manufacturing. The US Food and Drug Administration (FDA) and the Australian Therapeutic Goods Administration (TGA) require the same quality, performance and safety on reused devices as for original single-use devices, ${ }^{3,16,17}$ whereas the European Union has no uniform legislation. ${ }^{18}$ For instance, it is illegal in France to reuse a single-use device. In Canada, there is no federal regulation of single-use reprocessing, and the Canadian Agency for Drugs and Technologies in Health (CADTH) acknowledges that there are variations across provincial policies where some regions ban the reuse of all single-use devices and others allow it as long as it is carried out by licensed third-party reprocessors. ${ }^{19}$ Although the regulatory background prohibits reprocessing and reuse of single-use devices, this is common practice among hospitals and academic centres, and it should be noted that parties involved in it are potential targets of litigation. ${ }^{19}$

As they are single-use devices, many catheters are neither intended nor approved for reuse. The single-use classification for hydrophilic catheters, for example, is supported by findings in the literature describing safety concerns related to sterilization and reuse. ${ }^{20,21}$ Reuse may alter physical properties of the catheter material, and Kovindha et al. ${ }^{12}$ showed electron microscopic findings such as encrustation and increased stiffness after reuse of silicone catheters, even though they were intended for reuse. ${ }^{12}$

In summary, off-label reuse is not supported by legal requirements in Europe or the United States, or in Australia or Canada where reuse is currently common. There are general safety concerns related to reuse because the physical properties of the catheter material change and there is a risk of introducing bacterial contamination because of suboptimal cleaning and resterilization.

\section{Guideline recommendations}

Several published guidelines touch upon the reuse of catheters for intermittent catheterization. The European Association of Urology Nurses (EAUN) states in its guideline from 2013 that the gold standard in hospital and residential settings remains a new sterile catheter because of the risk of cross-infection. ${ }^{14}$ The guideline mentions that reuse of catheters may be considered for the community setting but summarizes the concerns mentioned in the literature for efficacy and compliance with the cleansing techniques that are practiced. The National Institute for Health and Care Excellence (NICE) updated its clinical guideline for infection prevention and control in 2012 and recommended offering a choice of either single-use hydrophilic or gel reservoir catheters for intermittent catheterization or, in the case of uncoated catheter use, an appropriate lubricant from a single-use container to minimize urethral trauma and infection. ${ }^{22}$ It further concludes that there is insufficient clinical evidence to recommend off-label reuse. ${ }^{22}$

Newman and Wilson ${ }^{23}$ (United States) encouraged the use of a new catheter at every occasion of intermittent catheterization to prevent UTI and recommended considering a hydrophilic catheter to prevent UTI in the case of traumatic catheterization and a single-use/closed system to prevent UTI in the case of poor catheterization technique and catheter care. The Infectious Disease Society of America's (IDSA) guideline from 2009 concluded that the evidence is poor to moderate for recommending multiple-use catheters instead of sterile single-use catheters with regard to bacteriuria or UTI and that there are insufficient data for recommending a cleaning method for multipleuse catheters. ${ }^{24}$ Howard ${ }^{6}$ described the factors behind the switch in the US Medicare Policy, where the Centers for Medicare and Medicaid 
Services of the Department of Health and Human Services eliminated mandatory reuse in intermittent catheterization in 2008. Factors mentioned are avoided risk owing to inadequate cleaning, improved patient care, enabled consumers' personal product choice and reduced risks for UTIs and thereby reduced health risks and costs. ${ }^{6}$ In summary, international guidelines do not explicitly recommend multiple-use over single-use catheters but instead propose patientoriented choice; ${ }^{14,21,22,25-28}$ for example, some studies stress poor evidence level for reuse ${ }^{24}$ and highlight issues related to reuse. $6,14,23$

\section{Costs}

Kovindha et al. ${ }^{12}$ acknowledged that disposable catheters are associated with less urethral trauma and infections and increased ease of use but that the high costs limit them to people in developed countries only. For patients in developing countries, reuse is often the only alternative and may be safe as long as proper catheterization and cleaning techniques are applied to reduce infection. ${ }^{12,29}$ Based on the findings from this review, the situation for developed countries differs depending on cost and reimbursement aspects, that is, some countries have chosen to reimburse single-use catheters (Europe and United States), whereas others are promoting reuse (Australia and Canada). In this context, it should be noted that cost comparisons for reuse and single use should not only consider the material costs for the catheters used but also costs related to add-on lubricants, sterilization methods, washing, complications, time spent and so on. For instance, a recent cost comparison between two catheterization techniques in the hospital setting found that the more expensive catheter was associated with a lower total cost for the hospital based on savings on additional lubricants used and nurse time spent. ${ }^{30}$ Furthermore, if reuse is associated with an increased number of adverse events, material cost savings are likely to be neutralized. ${ }^{4}$ It is also proposed that preference implications for costs and outcomes be acknowledged. ${ }^{26}$ Bermingham et al. ${ }^{26}$ showed that reuse of uncoated catheters was the most cost-effective option for intermittent catheterization but only in the case where less than four catheters a week are used. In the case of more frequent catheter use and/or of patient preference for single use, this may also be considered cost effective. $^{26}$

\section{Cleaning and resterilization}

A sterile or resterilized catheter should preferably be used to prevent infection, ${ }^{5}$ and proper cleaning of reusable catheters is recognized to be important in preventing unnecessary introduction of bacteria into the bladder. $^{31}$ However, several procedural complications are associated with reuse of catheters, and the concerns for efficacy and compliance with cleansing techniques raised by Vahr et al. ${ }^{14}$ are well grounded. For example, Sherbondy et al. ${ }^{8}$ reported great variations in how cleaning is practiced at home by patients, from daily sterilization to sterilization for less than once a week, and poor compliance with cleansing instructions. Poor compliance was also described by Chan et al., ${ }^{32}$ who concluded that the optimal cleansing technique remains to be established and that washing is not an absolute means to sanitize catheters. On the basis of an insufficiency of available disinfection methods, Bogaert et al. ${ }^{20}$ recommended patients on intermittent catheterization to use a sterile-packed and not previously used catheter. Kovindha et al. ${ }^{12}$ concluded that a shorter reuse time and proper cleansing and disinfection reduce the infection risk that is present for reuse. However, Hooton et al. ${ }^{24}$ found that there are insufficient data for recommending a cleaning method for multiple-use catheters. For example, Lavallee et al. ${ }^{33}$ proposed that catheters need to be rinsed under running, lukewarm tap water for at least $30 \mathrm{~s}$ immediately after use, and then dried, to sufficiently reduce bacteria, whereas others suggested the use of an antiseptic solution, ${ }^{12}$ microwaving in combination with antibacterial wash, ${ }^{32}$ dishwashing soap and water, ${ }^{31}$ alcohol immersion ${ }^{20}$ or hydrogen peroxide, bleach or betadine in water. ${ }^{34}$ Moy and Amsters ${ }^{15}$ even proposed that the cleaning method may be irrelevant as long as the catheter and the catheterization technique are clean. The wide diversity of cleaning and resterilization methods compromises the generalizability of results from studies involving reused catheters.

\section{UTI complications}

Several review publications ${ }^{11,13,14,21,24,26,35-37}$ in the literature conclude that there is a lack of evidence for a relation between catheter type, material and/or technique and frequency of UTI, and recently published studies on comparisons between reuse and single use indicate that there is no difference between the two alternatives but that these are compromised by being severely underpowered. ${ }^{10,38}$ In contrast, several reviews and studies support the use of a single-use hydrophilic catheter to reduce the risk of UTI; ${ }^{9,14,21,35,39-43}$ for example, a META analysis by Li et al. ${ }^{39}$ concludes a risk reduction of $64 \%$ associated with use of hydrophilic coating. Whichever the case, a lack of evidence is not equal to assumed safe use, clearly indicating that complications related to reuse should be further investigated. Meanwhile, Wyndaele ${ }^{29,44}$ summarized the essential basic principles for successful intermittent catheterization in his work from 2002 when concluding the need for good education of all involved, good patient compliance, use of a proper material and use of a noninfecting and nontraumatic technique adapted for the individual patient. Studies investigating UTI frequency are compromised by the facts that different UTI definitions are used (for example, antibiotic treated, self-reported, according to strict definition), different populations are studied (for example, spinal cord injuries, patients with multiple sclerosis, patients who practice intermittent catheterization) and different research perspectives are used (for example, retrospective study, observational surveys, randomized controlled trials). Although standardized definitions of UTI are proposed $^{24,45}$ and in many ways implemented, the UTI incidence reported in the literature is difficult to compare. UTI incidence for reuse could be expected to lie at $\sim 70-80 \%$ based on observational studies described in the literature. ${ }^{2,7,9,12}$ Reported UTI frequency for single-use populations is mainly viewed from the controlled environment that randomized controlled trials compose. ${ }^{39,40,42,43,46,47}$ Table 1 summarizes literature describing reuse/single-use-related UTI and urethral trauma complications reported per country, study type, population and catheter type/technique.

In summary, UTI incidence for single-use hydrophilic catheters could be expected to lie at $\sim 40-60 \%$ based on randomized controlled trials found in the literature. Compared with the observed UTI prevalence for reuse of $\sim 70-80 \%$ in observational studies, there seems to be a difference, although this is difficult to estimate because of the many compromising factors mentioned above.

\section{Haematuria/urethral complications}

Damage to the urethra is more likely to occur with an unlubricated catheter ${ }^{48}$ and findings reported in the literature support the use of a hydrophilic catheter to reduce the risk of microscopic haematuria/ urethral trauma. ${ }^{14,21,39,41}$ Guidelines also conclude that lubricants should be used to minimize pain and urethral trauma, $5,14,22,23,25,31$ and it is recommended that single-use containers with lubricants be used to avoid contamination. ${ }^{22}$ Trauma to the urothelium increases the risk of infection, ${ }^{31}$ and catheter-related pain may decrease 
Table 1 Complications related to reuse/single-use catheters per country, study type, population and catheter type/technique

\begin{tabular}{|c|c|c|c|c|c|c|}
\hline Reference & Country & Study type & Population & Catheter type/technique & UTI rate & Urethral trauma \\
\hline $\begin{array}{l}\text { Bolinger and } \\
\text { Engberg }^{7}\end{array}$ & USA & $\begin{array}{l}\text { Observational } \\
\text { survey }\end{array}$ & $\begin{array}{l}44 \text { Home IC users ( }>2 \text { months) because of } \\
\text { different reasons ( } 48 \% \mathrm{MS}, 21 \% \text { neuro- } \\
\text { genic bladder) }\end{array}$ & $\begin{array}{l}56 \% \text { reuse }(\sim 20 \\
\text { times })\end{array}$ & $77.2 \%$ & $22.7 \%$ (bleeding) \\
\hline $\begin{array}{l}\text { Woodbury } \\
\text { et al. }{ }^{9}\end{array}$ & Canada & $\begin{array}{l}\text { Observational } \\
\text { national survey }\end{array}$ & 505 Patients using IC because of $\mathrm{SCl}$ & $\begin{array}{l}\text { 47\% Reuse; } \\
74 \% \text { uncoated } \\
15 \% \text { hydrophilic } \\
11 \% \text { uncoated and } \\
\text { hydrophilic }\end{array}$ & $77 \%$ & - \\
\hline $\begin{array}{l}\text { Kovindha } \\
\text { et al. }{ }^{12}\end{array}$ & Thailand & $\begin{array}{l}\text { Observational, } \\
\text { cross-sectional } \\
\text { study }\end{array}$ & $28 \mathrm{SCl}$ injured men & $\begin{array}{l}\text { 100\% reuse; silicon } \\
\text { ( 3-year reuse) }\end{array}$ & $\sim 79 \%$ a & $11 \%$ (urethral bleeding) \\
\hline $\begin{array}{l}\text { Cardenas } \\
\text { and } \\
\text { Hoffman }^{42}\end{array}$ & USA & RCT & $45 \mathrm{SCl}$ patients (injury $\geqslant 6$ months ago) & $\begin{array}{l}100 \% \text { Single use; } \\
50 \% \text { hydrophilic } \\
50 \% \text { uncoated }\end{array}$ & $\begin{array}{l}54 \% \text { Hydrophilic, } \\
61 \% \text { uncoated }\end{array}$ & - \\
\hline $\begin{array}{l}\text { De Ridder } \\
\text { et al. }{ }^{33}\end{array}$ & Europe & $\mathrm{RCT}$ & 123 Patients with new SCl & $\begin{array}{l}100 \% \text { Single-use } \\
\text { assumed; } \\
50 \% \text { hydrophilic } \\
50 \% \text { uncoated }\end{array}$ & $\begin{array}{l}64 \% \text { Hydrophilic, } \\
82 \% \text { uncoated }\end{array}$ & $\begin{array}{l}69 \% \text { Hydrophilic, } 54 \% \\
\text { uncoated (haematuria) }\end{array}$ \\
\hline $\begin{array}{l}\text { Kannankeril } \\
\text { et al. }{ }^{50}\end{array}$ & USA & $\begin{array}{l}\text { Observational } \\
\text { (retrospective } \\
\text { chart review) }\end{array}$ & $\begin{array}{l}159 \text { Adult male IC users, mainly because } \\
\text { of BPH }\end{array}$ & $100 \%$ reuse; red rubber & $40.3 \%^{b}$ & - \\
\hline $\begin{array}{l}\text { Bakke } \\
\text { et al. }{ }^{46}\end{array}$ & Norway & Observational & $\begin{array}{l}170 \text { Long-term IC users, mainly because } \\
\text { of } \mathrm{SCl}\end{array}$ & $\begin{array}{l}\text { 99\% single-use; } 91 \% \\
\text { hydrophilic }\end{array}$ & $35 \%$ & - \\
\hline
\end{tabular}

Abbreviations: BPH, benign prostatic hyperplasia; IC, intermittent catheterization; MS, multiple sclerosis; NA, not applicable; RCT, randomized controlled trial; SCI, spinal cord injury; UTI, urinary tract infection.

aDuring the most recent year, $21 \%$ of the patients did not show any signs of infections or urethral problems.

bSample includes patients who performed IC occasionally, for example, once per month.

compliance to therapy. For instance, Wilde et al. ${ }^{2}$ published figures on catheter-related pain reported by $38 \%$ patients where many did not use lubrication.

The reported incidence of microtrauma varies depending on the evaluation method (for example, self-reported bleeding, microscopic observation) and study set-up. See Table 1 for a summary of relevant evidence related to reuse/single-use catheters.

In summary, microtrauma can be expected to occur in $20-30 \%$ of the patients practicing intermittent catheterization, and it can be assumed that lower figures are related to hydrophilic coating or use of lubrication; for example, Li et al..$^{39}$ conclude that there is a $43 \%$ risk reduction of haematuria associated with use of hydrophilic coating.

\section{Patient preference}

In reviewing the literature, it can be concluded that many authors argue for user choice in the product selection for intermittent catheterization. One product is unlikely to suit everyone, and intermittent catheterization users require products that meet their individual preferences and needs. ${ }^{2,14,21,22,25-28}$ It is recommended that the catheter method be matched to patients' ability to maintain cleanliness; for instance, if the patient has limited access to running water throughout the day, a single-use catheter may be more appropriate. ${ }^{21}$ Bermingham et al. ${ }^{26}$ among others conclude that the patients should be offered a choice between reuse and single-use and different catheter types. However, there is sometimes no choice for the patient. Chick et al. ${ }^{28}$ observed that $83 \%$ of the patients who practiced reuse of a PVC catheter found it unacceptable but that $88 \%$ would continue to use it as this was the only method provided by the healthcare system. Similar patterns were seen by Wilde et al., ${ }^{2}$ who concluded that many patients who were prescribed intermittent catheterization do not have complete medical insurance coverage or knowledge of different catheter options. Patients report that single-use catheters are more convenient ${ }^{49}$ and make catheterization away from home easier, ${ }^{28}$ and that it is inconvenient and unaesthetic to clean catheters away from home. ${ }^{24}$ Bolinger and Engberg ${ }^{7}$ show that the most significant barrier for practicing intermittent catheterization is access to public bathrooms and inadequate shelves or countertops for placing supplies in preparation for intermittent catheterization. This is confirmed by Wilde et $a l^{2}$ who described public bathrooms as being inaccessible and poorly designed and cleaned. ${ }^{2}$ Patient choice is 
highly individual but some studies conclude that patients prefer single-use hydrophilic catheters. ${ }^{26,41,43,47}$ Bennet $^{48}$ proposed that a single-use and a mess-free catheter may contribute to good patient compliance. This is crucial to reducing risk factors for UTI, such as adequate catheterization frequency to maintain low bladder volumes and reduced distension.

\section{DISCUSSION}

Future research

As mentioned, a lack of evidence is not equal to assumed safe use, and thus complications related to reuse should be further investigated. The most clinically relevant and primary outcome measure should be the incidence of symptomatic UTI, as specified for instance in the NICE guideline. ${ }^{22}$ Thus, for future randomized controlled trials investigating reuse versus single-use catheters, it is necessary to estimate an expected difference in UTI frequency. Li et al. ${ }^{39}$ report $50 \%$ for hydrophilic catheters as compared with $72 \%$ for uncoated PVC catheters. Based on this review, a potentially greater difference may be expected for single-use versus reuse, that is, $40-60 \%$ for single-use hydrophilic catheters and $70-80 \%$ for reuse uncoated PVC catheters. The expected difference in UTI frequency will have a major impact on the required sample size and it is recommended to have a parallel group study with at least 132 patients/group and additional patients to cover for the dropout in order to test the difference level proposed by Li et al. ${ }^{39}$ This number would enable detection of a $40 \%$ versus $60 \%$ calculated difference in UTI frequency with a power of $90 \%$.

Furthermore, standardized symptomatic UTI definitions and a homogeneous population are recommended to best capture a potential treatment difference between single-use or reuse catheters. Worth mentioning is the intrinsic ethical and regulatory dilemma in comparing single-use catheters to reuse of catheters intended for single use, that is, off-label reuse is proposed from a cost-saving perspective putting the patient at potential risk why both ethical and regulatory clearance is necessary before such study commences.

Based on the high number of patients needed to investigate UTI frequency between single use and reuse and the ethical/regulatory challenges in doing so, it is recognized that smaller pilot studies may also be valuable in investigating, for instance, compliance to cleaning protocol, bacterial contamination, changed material properties associated with reuse and so on. Furthermore, if clinical efficacy could be proven with single use, further studies investigating effectiveness in general and cost effectiveness in particular should follow.

\section{Summary of evidence}

$\mathrm{Al}$ though similar legal background and guideline recommendations prevail, the prevalence of reuse varies between regions and is very often driven by financial issues. For the United States, Canada and Australia, the prevalence of at least $50 \%$ seems to be a fair estimate. Both off-label reuse and reuse of catheters intended for multiple uses occur. The former is not legally supported. There seems to be no consensus on how many times a catheter should be reused and, although one catheter per day is recommended by some, it varies between 1 and 7 days and even up to longer periods of months and years.

Single-use catheters are more expensive than a reused catheter, but cost comparisons should not only consider the material costs for the catheters but also costs related to add-on lubricants, sterilization methods, washing, complication levels, time spent and patient preference. No uniform recommendation for cleaning procedures for reused catheters exists, and poor compliance and efficacy have been reported, increasing the risk for introducing bacterial contamination when performing intermittent catheterization. Even though there are conflicting findings in the literature, there is support for using single-use hydrophilic catheters to reduce the risk of UTI and urethral trauma. The UTI incidence for single-use hydrophilic catheters can be expected to lie at $\sim 40-60 \%$ based on randomized controlled trials reported in the literature. Compared with the observed UTI prevalence for reuse of $\sim 70-80 \%$ found in observational studies, there seems to be a difference, although it is difficult to estimate owing to many compromising factors.

\section{Limitations}

The findings in this review are limited by many compromising factors affecting the generalizability of the results. In particular, different ways of defining and measuring complications exists (for example, UTI, urethral trauma and so on), different populations are studied and different research perspectives are used. In addition, reuse of catheters is practiced in a number of ways, complicating the situation even further. For this reason, the comparative results from the review should be carefully considered if used as a basis for clinical decision making.

\section{CONCLUSIONS}

Further clinical studies are needed to verify/reject safety differences between reuse/single-use catheters and, while awaiting more evidence, it is recommended to use a confirmed safe, noninfecting and nontraumatic technique for intermittent catheterization. It can be concluded that patients practicing intermittent catheterization prefer to have a choice and should be able to choose the catheters that best fit their needs and preference, regardless of whether it might be a more expensive choice. This may be expected to increase compliance to the therapy and ensure long-term success and cost effectiveness of intermittent catheterization.

\section{DATA ARCHIVING}

There were no data to deposit.

\section{CONFLICT OF INTEREST}

The study is sponsored by Wellspect HealthCare. Author discloses that she receives financial and material support as a manufacturer employee. No specific compensation is linked to the publication of this study.

\section{ACKNOWLEDGEMENTS}

This study is sponsored by Wellspect HealthCare.

1 Nazarko L. Intermittent self-catheterisation: past, present and future. Br J Community Nurs 2012; 17: 408: 410-12.

2 Wilde $\mathrm{MH}$, Brasch J, Zhang Y. A qualitative descriptive study of self-management issues in people with long-term intermittent urinary catheters. J Adv Nurs 2011; 67: 1254-1263.

3 Day $P$. What is the evidence on the safety and effectiveness of the reuse of medical devices labelled as single-use only? NZHTA Tech Brief Series 2004; 3 Available from http://www.otago.ac.nz/christchurch/otago014014.pdf

4 Shuman EK, Chenoweth CE. Reuse of medical devices: Implications for infection control. Infect Dis Clin N Am 2012; 26: 165-172.

5 Wyndaele JJ, Madersbacher H, Kovindha A. Conservative treatment of the neuropathic bladder in spinal cord injured patients. Spinal Cord 2001; 39: 294-300.

6 Howard M. U.S. Medicare policy change in catheter guideline improves patient care in home and hospice setting. Caring 2009; 28: 22-25.

7 Bolinger R, Engberg S. Barriers, complications, adherence, and self-reported quality of life for people using clean intermittent catheterization. J Wound Ostom Continence Nurs 2013; 40: 83-89. 
8 Sherbondy AL, Cooper CS, Kalinowski SE, Boyt MA, Hawtrey CE. Variability in cathete microwave sterilization techniques in a single clinic population. J Urol 2002; 168 562-564.

9 Woodbury MG, Hayes KC, Askes HK. Intermittent catheterization practices following spinal cord injury: a national survey. Can J Urol 2008; 15: 4065-4071.

10 Leek H, Stephenson Z, Reus A, Karantanis E, Moore KH. Clean intermittent selfcatheterisation: a randomised controlled crossover trial of single-use versus multiple re-use of non-coated catheters; is cystitis rate altered? Neurourol Urodyn 2013; 32: 759-760.

11 Getliffe K, Fader M, Allen C, Pinar K, Moore KM. Current evidence on intermittent catheterization. Sterile single-use catheters or clean reused catheters and the incidence of UTI. J Wound Ostomy Continence Nurs 2007; 34: 289-296.

12 Kovindha A, Mai WN, Madersbacher H. Reused silicone catheter for clean intermittent catheterization (CIC): is it safe for spinal cord-injured (SCI) men? Spinal Cord 2004; 42: 638-642.

13 Medical Advisory Secretariat. Hydrophilic catheters: an evidence-based analysis. Ont Health Technol Assess Ser 2006; 6: 1-31.

14 Vahr S, Cobussen-Boekhorst H, Eikenboom J, Geng V, Holroyd S, Lester M et al. Evidence-based guideline for best practice in urological health care. Catheterisation. Urethral intermittent in adults. Dilatation, urethral intermittent in adults. EAUN guideline 2013, Available from http://www.uroweb.org/fileadmin/EAUN/guidelines/ 2013_EAUN_Guideline_Milan_2013-Lr_DEF.pdf.

15 Moy MT, Amsters D. Urinary tract infection in clients with spinal cord injury who use intermittent clean self catheterisation. Aust J Adv Nurs. 2004; 21: 35-40.

16 FDA.gov. Available from http://www.fda.gov/MedicalDevices/DeviceRegulationandGuidance/ReprocessingofSingle-UseDevices/.

17 TGA.gov.au. Australian regulatory guideline for medical devices (ARGMD) part 2-Premarket. Available from http://www.tga.gov.au/pdf/devices-argmd-p2.pdf

18 Eucomed.org. Available from http://www.eucomed.org/key-themes/patients-safety/ reuse-of-single-use-devices.

19 Larose E. Legal implications of single-use medical device reprocessing. Healthc $Q$ 2013; 16: 48-52.

20 Bogaert GA, Goeman L, de Ridder D, Wevers M, Ivens J, Schuermans A. The physical and antimicrobial effects of microwave heating and alcohol immersion on catheters that are reused for clean intermittent catheterisartion. Eur Urol 2004; 46 641-646.

21 Hill TC, Baverstock R, Carlson KV, Estey EP, Gray GJ, Hill DC et al. Best practices for the treatment and prevention of urinary tract infection in the spinal cord injured population: the Alberta context. Can Urol Assoc J 2013; 7: 122-130.

22 National Clinical Guideline Centre (UK). Infection: Prevention and control of healthcare-associated infections in primary and community care: Partial update of NICE Clinical Guideline 2. Royal College of Physicians: London, 2012, National Institute for Health and Clinical Excellence: Guidance. Available from http://publications.nice. org.uk/infection-cg139.

23 Newman D, Willson MM. Review of intermittent catheterization and current best practices. Urol Nurs 2011; 31: 12-29.

24 Hooton TM, Bradley SF, Cardenas DD, Colgan R, Geerlings SE, Rice JC et al. Diagnosis, prevention, and treatment of catheter-associated urinary tract infection in adults: 2009 International Clinical Practice Guidelines from the Infectious Disease Society of America. Clin Infect Dis 2010; 50: 625-663.

25 Woodward S. Dos and don'ts of intermittent self-catheterisation. Br J Nurs 2013; 22: S10.

26 Bermingham S, Hodgkinson S, Wright S, Hayter E, Spinks J, Pellowe C. Intermittent self catheterization with hydrophilic, gel reservoir, and non-coated catheters: a systematic review and cost effectiveness analysis. BMJ 2013; 346: e8639.

27 Kelly L, Spencer S, Barret G. Using intermittent self-catheters: experiences of people with neurological damage to their spinal cord. Disabil Rehabil 2014; 36 220-226.

28 Chick HE, Hunter KF, Moore KN. Parent and child experiences using a hydrophilic or reused PVC catheter for intermittent catheterization. J Clin Nurs 2012; 22 516-520.

29 Wyndaele JJ. Intermittent catheterization: which is the optimal technique? Review. Spinal Cord 2002; 40: 432-437.

30 Goessaert A, Antoons S, van den Driessche M, Tourchi A, Pieters R, Everaert K. No touch intermittent catheterization: caregiver point of view on sterility errors, duration, comfort and costs. J Adv Nurs 2013; 69: 2000-2007.

31 Heard L, Buhrer R. How do we prevent UTI in people who perform intermittent catheterization? Rehabil Nurs 2005; 30: 44-45. 61.
32 Chan JL, Cooney TE, Schober JM. Adequacy of sanitization and storage of catheters for intermittent use after washing and microwave sterilization. J Uro 2009; 182 (4 Suppl), 2085-2089.

33 Lavallée DJ, Lapierre NM, Henwood PK, Pivik JR, Best M, Springthorpe VS et al. Catheter cleaning for re-use in intermittent catherization: new light on an old problem. SCl Nurs 1995; 12: 10-12.

34 Kurtz MJ, van Zandt K, Burns JL. Comparison study of home catheter cleaning methods. Rehabil Nurs 1995; 20: 212-214. 217.

35 Ercole FF, Macieira TG, Wenceslau LC, Martins AR, Campos CC, Chianca TC Integrative review: evidences on the practice of intermittent/indwelling urinary catheterization. Rev Lat Am Enfermagem 2013; 21: 459-468.

36 Wyndaele JJ, Brauner A, Geerlings SE, Koves B, Tenke P, Bjerklund-Johanson TE. Clean intermittent catheterization and urinary tract infection: review and guide for future research. BJU Int 2012; 110: E910-E917.

37 Moore KN, Fader M, Getliffe K. Long-term bladder management by intermittent catheterisation in adults and children. Cochrane Database Syst Rev 2007; 17: CD006008.

38 Moore KN, Kiddoo D, Sawatzky B, Afshar K, Dharamsi N, Bascu C et al. Randomised crossover trial of hydrophilic single use versus PVC multiuse catheters for $\mathrm{CIC}$ in children with neural tube defects (Spina Bifida). Neurourol Urodyn 2013; 32: 760-761.

39 Li L, Ye W, Ruan H, Yang B, Zhang S, Li L. Impact of hydrophilic catheters on urinary tract infections in people with spinal cord injury: systematic review and meta-analysis of randomized controlled trials. Arch Phys Med Rehabil 2013; 94: 782-787.

40 Cardenas D, Moore K, Dannels-McClure A, Scelza WM, Graves DE, Brooks M et al. Intermittent catheterization with a hydrophilic-coated catheter delays urinary tract infections in acute spinal cord injury: a prospective, randomized, multicenter trial. $P M$ R 2011; 3: 408-417.

41 Chartier-Kastler E, Denys P. Intermittent catheterization with hydrophilic catheters as a treatment of chronic neurogenic urinary retention. Neurourol Urodyn 2011; 30 21-31.

42 Cardenas DD, Hoffman JM. Hydrophilic catheters versus noncoated catheters for reducing the incidence of urinary tract infections: a randomized controlled trial. Arch Phys Med Rehabil 2009; 90: 1668-1671.

43 De Ridder DJMK, Everaert K, Fernández LG, Valero JV, Durán AB, Abrisqueta ML et al. Intermittent catheterisation with hydrophilic-coated catheters (SpeediCath) reduces the risk of clinical urinary tract infections in spinal cord injured patients: a prospective randomised parallel comparative trial. Eur Urol 2005; 48: 991-995.

44 Wyndaele JJ. Complications of intermittent catheterization: their prevention and treatment. Original Article. Spinal Cord 2002; 40: 436-541.

45 Goetz LL, Cardenas DD, Kennelly M, Bonne Lee BS, Linsenmeyer T, Moser C et al. International spinal cord injury urinary tract infection basic data set. Spinal Cord 2013; 51: 700-704.

46 Bakke A, Digranes A, Høisæter PA. Physical predictors of infection in patients treated with clean intermittent catheterization: a prospective 7-year study. Br J Urol 1997; 79: 85-90.

47 Vapnek JM, Maynard FM, Kim J. A prospective randomized trial of the Lofric hydrophilic coated catheter versus conventional plastic catheter for clean intermittent catheterization. J Urol 2003; 169: 994-998.

48 Bennett E. Intermittent self-catheterisation and the female patient. Nurs Stand 2002; 17: $37-42$.

49 Doherty W. The Aquacath hydrophilic coated single-use urinary catheter. Br J Nurs 1998; 7: 1332: 1334-1336.

50 Kannankeril AJ, Lam HT, Reyes EB, McCartney J. Urinary tract infection rates associated with re-use of catheters in clean intermittent catheterization of male veterans. Urol Nurs 2011; 31: 41-48.

(c) (i) This work is licensed under a Creative Commons Attribution 3.0 Unported License. The images or other third party material in this article are included in the article's Creative Commons license, unless indicated otherwise in the credit line; if the material is not included under the Creative Commons license, users will need to obtain permission from the license holder to reproduce the material. To view a copy of this license, visit http:// creativecommons.org/licenses/by/3.0/ 